\title{
War Wounded and Victims of Traffic Accidents in a Surgical Hospital in Africa: An Observation on Injuries
}

\author{
Martin Schneider, MSc
}

\author{
International Committee of the Red Cross, \\ Geneva, Switzerland \\ Correspondence: \\ Martin Schneider, MSc \\ Health Unit \\ International Committee of the Red Cross \\ 12, avenue de la Paix \\ 1202 Geneva, Switzerland \\ E-mail: martin.schneider@unige.ch
}

Conflicts of interest: none

Keywords: Africa; conflict; traffic accidents; war wounded

Abbreviation:
ICRC: International Committee of the Red
Cross

Received: February 16, 2015

Revised: May 24, 2015

Accepted: May 29, 2015

Online publication: October 21, 2015

doi:10.1017/S1049023X15005269

\begin{abstract}
Introduction: Weapon injuries in armed conflict are likely to receive medical attention. Other types of injuries, like traffic accidents, continue to occur during armed conflict.

Problem: Injuries caused by weapons and by traffic accidents require treatment, but reports and figures to help in prioritizing care are scarce.

Methods: In a prospective observational study, all emergency patients admitted to the surgical ward in a public hospital of the Central African Republic were evaluated for the cause of their main injury. The proportion of patients injured by weapons and by traffic accidents was analyzed with respect to the level of violence.

Results: Seventy-eight patients were included in this study. Weapon injuries accounted for $50(64 \%)$ admissions and traffic accidents for 28 (36\%). These proportions varied significantly according to the weekly level of violence $\left(\chi^{2}=46.8 ; P<.001\right)$.

Conclusion: People injured in traffic accidents are an important, but overlooked, drain on surgical resources in low-income countries with armed conflict. Their proportion in relation to weapon wounded fluctuates with the level of violence. Humanitarian medical organizations might prepare themselves not only for weapon injuries, but also for wounds caused by traffic accidents.
\end{abstract}

Schneider M. War wounded and victims of traffic accidents in a surgical hospital in Africa: an observation on injuries. Prehosp Disaster Med. 2015;30(6):618-620.

\section{Introduction}

During armed conflict, injuries caused by weapons attract much public and medical attention. Reports on wounded people make it into international news, and medical journals regularly report on conflict, health, and injuries. ${ }^{1}$ For decades, humanitarian organizations have developed and run surgical programs in countries affected by armed conflict and have accumulated wide experience in the treatment of injuries inflicted by various types of weapons.

Morbidity and mortality due to traffic accidents have increased in many developing countries as faster means of transport have become more available and affordable. According to the World Health Organization (WHO; Geneva, Switzerland), traffic accidents are a public health issue. ${ }^{2}$ During times of armed conflict, people still travel. This ongoing mobility exposes them to the risk of traffic accidents. In contrast to deaths and injuries directly related to violence, victims of traffic accidents rarely are reported by local and international media. Similarly, they are seldom a priority for humanitarian medical interventions or for epidemiological research.

Few data exist on the health impact of traffic accidents compared to weapon injuries in areas of conflict. ${ }^{3}$ If available, information is often limited to anecdotal evidence. In this context of scarce data, the present observational study aimed to record, systematically and prospectively, injuries caused by weapons and by traffic accidents, as well as to relate the outcomes of the hospitalized patients. The challenging security situation and difficult working conditions allowed for the collection of data during one month only. 


\section{Methods}

Setting

The Central African Republic is one of the least-developed countries. In 2013, gross national income per person was US $\$ 320 /$ year and life expectancy was 49 years. ${ }^{4} \mathrm{~A}$ long-standing armed conflict between religious and political factions has exacerbated since 2013.

The capital Bangui has about 750,000 inhabitants. The Community Hospital is one of its larger public hospitals for adults. It offers medical, obstetrical, and surgical care. The International Committee of the Red Cross (ICRC; Geneva, Switzerland) has been working in this hospital since late January 2014 with two to three expatriate surgical teams to provide better care for victims of violence.

\section{Data Collection and Analysis}

From February 28, 2014 through March 27, 2014, all surgical patients admitted through the accident and emergency department in the Community Hospital in Bangui were included into this observational study. Patients hospitalized for personal security reasons only and patients dead on arrival were excluded. All patients gave oral consent for the inclusion in the study. The patient's demographic information, the location of the main injury (coded using the International Classification of Diseases, $10^{\text {th }}$ version ${ }^{5}$ ), and the cause of the injury (gunshot, grenade, bladed weapon, or traffic accident) were recorded. The patients were followed during hospitalization, and their outcome (recovery, permanent disability, or death) was recorded prospectively in an anonymized database. Proportions were compared by the $\chi^{2}$-test, group means by Student's t-test, using the statistical package of Stata (StataCorp; College Station, Texas USA).

\section{Results}

\section{Study Population}

There were 78 patients, $16(21 \%)$ women and $62(79 \%)$ men. Mean age was 31 years, ranging from 12 years to 70 years. Six $(8 \%)$ patients died after their admission to the hospital, and five (6\%) had a permanent disability. Grenades had caused the injury for $13(17 \%)$, gunshots for $29(37 \%)$, bladed weapon for eight (10\%), and traffic accidents for $28(36 \%)$ patients.

Patients injured by weapons were younger than the victims of traffic accidents (mean age $=28$ years vs 36 years; $\mathrm{t}=2.95$; $P=.004$ ) and tended to be male (odds ratio $=2.1 ; 95 \%$ confidence interval, 0.59-7.42). The duration of hospitalization tended to be shorter for victims of traffic accidents (median $=$ two days vs five days).

\section{Injuries and Intensity of Violence}

Figure 1 represents the distribution of causes of injuries over time. At the beginning and the end of the observation period, the security situation in Bangui was more tense than during the weeks of March $3^{\text {rd }}$ and March $10^{\text {th }} .6$ Accordingly, injuries inflicted by weapons were less frequent during the weeks with better security when traffic accidents accounted for more than half of the admitted patients $\left(\chi^{2}=46.8 ; P<.001\right)$.

\section{Discussion}

This study undertaken in Bangui during the armed conflict in early 2014 showed that traffic accidents were a frequent reason for surgical hospitalization, particularly during periods with lessintense violence. There was an inverse relation between the intensity of violence and the proportion of patients admitted due

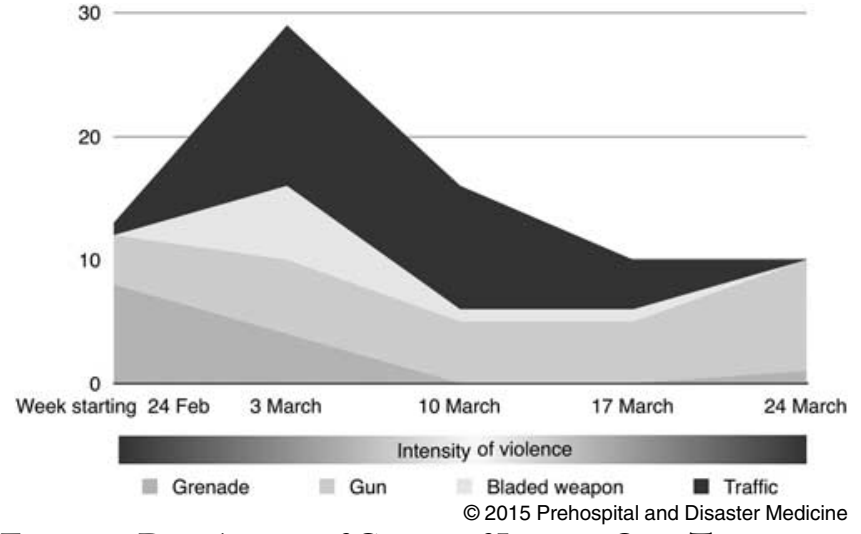

Figure 1. Distribution of Causes of Injuries Over Time.

to traffic accidents. During days with heavy fighting, many people preferred not to travel and were therefore safe from traffic accidents.

More men than women were injured by weapons. Usually, men are more actively engaged than women in an armed conflict. The ICRC treats patients without discrimination ${ }^{7}$ and has found the same gender imbalance in various war hospitals. ${ }^{8}$

The relatively small sample size limits the internal validity of the results. However, the difficult and unstable situation in Bangui did not allow for a larger sample size without compromising the quality and precision of prospective data gathering. Nevertheless, the findings may contribute to a better understanding of the epidemiology of injuries and to generate evidence required to address the surgical needs in low-income countries with armed conflict. ${ }^{9}$

The study indicates that in conflict, injuries unrelated to the fighting are also a major health issue. While medical humanitarian organizations are ready and well-prepared to provide surgical care to war wounded patients, often for free, they are less likely to have the same approach to injuries of other types. ${ }^{10}$ These organizations should prepare to take care not only of weapon injuries, but also of injuries due to traffic accidents. This implies appropriate clinical expertise, surgical equipment, and an adapted public health approach. ${ }^{11}$

\section{Conclusion}

This observational study found that during a conflict in a lowincome African country, traffic accidents caused relevant morbidity and mortality, along with injuries and deaths related to weapons. Traffic accidents particularly were frequent in periods with less-intense violence. The proportion of hospitalized patients from traffic accidents can vary with the intensity of the conflict, but it is substantial enough to require resources for adequate care. Medical humanitarian organizations should prepare to take care not only of weapon injuries, but also of injuries due to traffic accidents. This implies appropriate clinical expertise, surgical equipment, and an adapted public health approach. Eventually, this might require funding strategies that focus on wider health consequences of armed conflict.

\section{Acknowledgements}

Thanks to Dr. Pierre Alfred Issa Mapouka, Director of the Community Hospital, and to the team of the emergency department, for their support. Dr. Robin Coupland provided valuable comments. 


\section{References}

1. The war on Syrian civilians. Lancet. 2014;383(9915):383.

2. World Health Organization. Global Status Report on Road Safety 2013: Supporting a Decade of Action. Geneva, Switzerland: World Health Organization; 2013.

3. Sosa LM, Bhatti JA. Road traffic injuries in conflict areas. Inj Prev. 2013;19(5):367.

4. The World Bank. Data: Central African Republic. 2014. World Bank Web site. http://data.worldbank.org/country/central-african-republic. Accessed November 30, 2014.

5. World Health Organization. International Statistical Classification of Diseases and Related Health Problems. Geneva, Switzerland: World Health Organization; 2010.

6. UN Office for the Coordination of Humanitarian Affairs. Central African Republic: Situation Report No. 19 (as of 2 April 2014). Bangui: OCHA. http://reliefweb.int/ report/central-african-republic/central-african-republic-car-situation-report-no19-2april-2014. Published April 2, 2014. Accessed November 30, 2014.
7. International Committee of the Red Cross. The ICRC's Mandate and Mission. 2010. ICRC Web site. http://www.icrc.org/eng/who-we-are/mandate/overview-icrcmandate-mission.htm. Accessed November 30, 2014.

8. Coupland RM, Samnegård HO. Effect of type and transfer of conventional weapons on civilian injuries: retrospective analysis of prospective data from Red Cross hospitals. BMJ. 1999;319(7207):410-412.

9. Clarke M, Allen C, Kayabu B. Helping people make well-informed decisions before, during, and after disasters: the Evidence Aid initiative. Cochrane Database Syst Rev. 2011;12:ED000036.

10. Chu K, Trelles M, Ford N. Rethinking surgical care in conflict. Lancet. 2010;375 (9711):262-263.

11. Ozgediz D, Jamison D, Cherian M, McQueen K. The burden of surgical conditions and access to surgical care in low- and middle-income countries. Bull World Health Organ. 2008;86(8):646-647. 